\title{
Synergy of Morgagni and Hiatus Hernia
}

\author{
Menduh Oruç', Recep Dursun², Atalay Şahin', Abdullah Böyük, Ahmet Erbey', \\ Ahmet Sizlanan' \\ From the Departments of Thoracic Surgery ${ }^{1}$, Emergency Medicine ${ }^{2}$ and General Surgery ${ }^{3}$; \\ Dicle University, Diyarbakır, Turkey.
}

\section{Abstract:}

Morgagni hernia is an extremely rarely seen pathology and observation of it in advanced ages is even a rarer situation. Morgagni hernia, asymptomatically progressing in adult age can turn into symptomatic situation in advanced ages. In a 75-year old woman who applied with serious respiration difficulty, dysphagia and dyspepsia complaints, Morgagni hernia, along with hiatal hernia, was diagnosed. Laparotomy showed omentum passing to thorax. This report highlights the rare presentation of Morgagni and hiatus hernia.

Key words: Hiatal Hernia, Diaphragmatic Hernia, Congenital, Omentum, Laparotomy, Dyspnea, Humans.

\section{Introduction}

Morgagni hernia, seen in antero-lateral section of diaphragm, is a congenital defect occurring because of failure of diaphragmatic cruralis and costal elements to develop from Larrey interval, and this makes up 2-3\% of congenital diaphragm hernia $[1,2]$. This hernia may cause respiratory distress in newborns and is encountered in repeating pulmonary infections in children. Those seen in advanced ages display nonspecific symptoms such as swelling and dyspepsia. Dyspnoea accompanies in advanced cases. We present a case of Morgagni and hiatus hernia in an aged woman.

\section{Case Report}

A 75-year old female patient applied to our emergency service with serious respiratory difficulty, dysphagia and dyspepsia. On physical examination she was conscious, oriented and apyretic $\left(37.2^{\circ} \mathrm{C}\right)$. She had heart sounds of 87 beats per minute and a respiratory rate of $38 /$ minute. Her abdomen examination revealed tenderness in left hypochondriac area which increased on deep palpation. Chest examination revealed bilateral decrease in air entry in basal areas. Due to a suspicious image in chest radiography taken in another center, we performed thoracic computed tomography. CT scan showed Morgagni hernia in addition to hiatal hernia in the patient, along with a mass in fat density filling approximately $50 \%$ of right hemi-thorax [Fig. 1].

The patient was hospitalized in the thoracic surgery service following gastrointestinal endoscopy

Corresponding Author: Dr. Recep Dursun

Email: drrecepdursun@hotmail.com

Received: November 25, 2014 | Accepted: January 8, 2015 | Published Online: January 25, 2015

This is an Open Access article distributed under the terms of the Creative Commons Attribution License (creativecommons.org/licenses/by/3.0)

Conflict of interest: None declared | Source of funding: Nil | DOI: http://dx.doi.org/10.17659/01.2015.0009 
with the diagnosis of hiatal hernia and a mass in the right hemi-thorax. Laparotomy revealed omentum completely passing into the thorax. Omentum was drawn from the thorax carefully through the $2 \times 2$ $\mathrm{cm}$ retrosternal defect [Fig.2]. It was seen that there was no hernia vesicle. The defect was repaired with silk suture. Subsequently, the stomach which passed to the thorax was drawn to the abdomen and hiatal hernia was fixed as well. In order to prevent postoperative pneumothorax, air within the thorax was sucked by vacuum aspirator. There was no postoperative complication seen in the patient and she was discharged on day 7. On follow up done at one month, patient was asymptomatic with no complains of dyspepsia and dyspnea.

\section{Discussion}

This rare diaphragm hernia, described by Giovanni Battista Morgagni as postmortem and called by his name, is seen right behind the cisternae in Larrey interval. It occurs because diaphragm, septum transversum and costa are not merged $[2,3]$. Increase in intraperitoneal pressure causes herniation. Diagnosis of small defects due to nonspecific digestion and respiration problems may take years. Amplitude of the defect may lead to acute intestinal obstruction. In the presented patient, although there was hiatal hernia, respiratory difficulty was added in time to gastrointestinal symptoms. Omentum, which passed from the defect to the thorax in time, decreased hemithorax volume and led to dyspnea.

This disorder may not be easily diagnosed based on history and physical examination. A high degree of clinical suspicion is required and diagnosis can be missed easily in small defects and obstruction may develop in organs that pass from the defect. Most Morgagni hernia cases are asymptomatic although diagnostic opportunities do help in arriving at early diagnosis. Small defects may develop after blunt trauma and become symptomatic. According

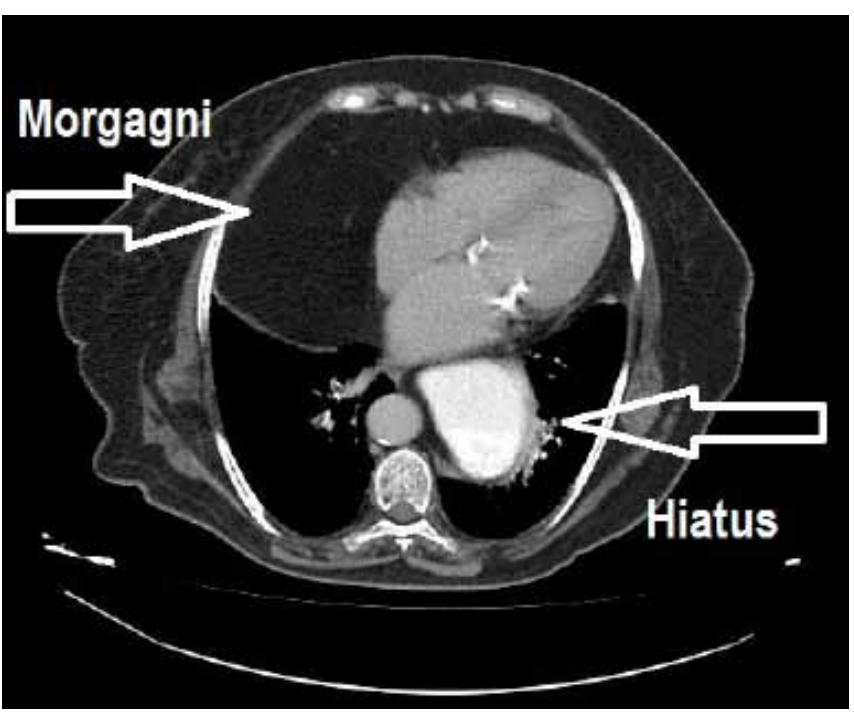

Fig.1: Coexistence of both hernias in the computed tomography scan.

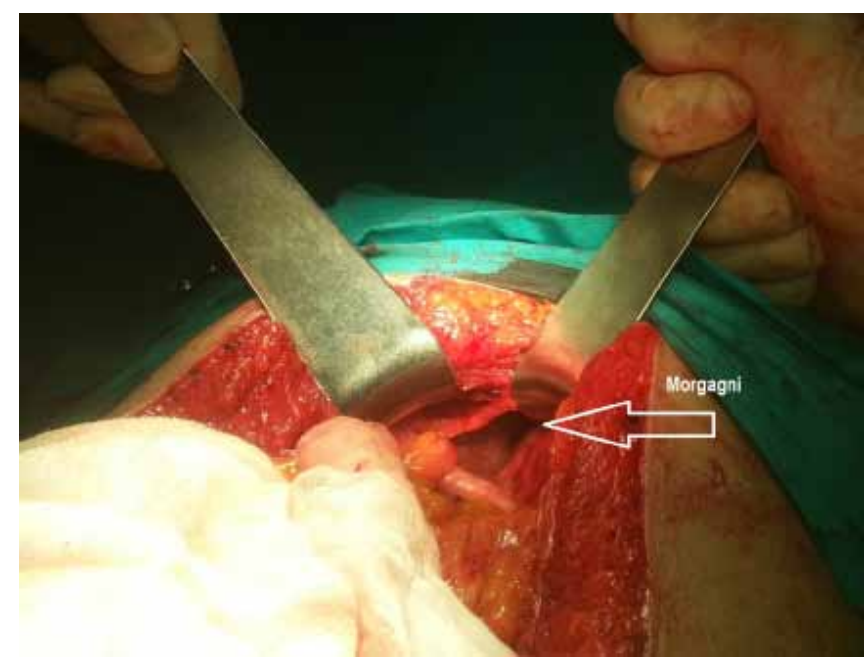

Fig.2: Intra-operative view showing both hernias.

to the extent of the defect, stomach, intestines and liver in addition to omentum may also pass into the thorax. In the differential diagnosis, intra-thoracic tumor, atelectasia, pneumonia and pericardial cysts are considered.

Computerized thorax tomography provides more detailed information in comparison to the 
chest radiography and baric examinations. When the intestines enter into thorax, diagnosis is made easily, however, when only omentum passes into thorax, diagnosis may be challenging [4]. In diagnostic difficulties, scintigraphy and MRI are used as well.

Surgical restoration is required in order to prevent feasible complications. Since our patient had hiatal hernia as well, she was approached with laparotomy. Restoration can be made by the thorax, preperitoneal approach and laparascopically as well $[3,5]$. There are hernia vesicles in most of the cases. On the other hand, there was none in the presented patient. Morgagni hernia, progressing asymptomatically, can become symptomatic in advanced ages and clinicians should maintain a high index of suspiction in advancing dyspnea and dyspepsia cases.

\section{Conclusion}

Synergy of Morgagni and hiatus hernia is rare. The diagnosis may be made preoperatively with the help of imaging modalities. Surgical resection is mostly curative.

\section{References}

1. Laennec RTH. Traite' du diagnostic des maladies des poumons et du coeur. Tome Second, Paris: Brosson and Chaude, 1819.

2. Light RW. Diseases of the pleura. Current Opinion in Pulmonary Medicine. 1995;1(4):313-317.

3. Henry M, Arnold T, Harvey J. Pleural Diseases Group, Standards of Care Committee, British Thoracic Society. BTS guidelines for the management of spontaneous pneumothorax. Thorax. 2003;58:39-52.

4. Gupta D, Hansell A, Nichols T, Duong T, Ayres JG, Strachan D. Epidemiology of pneumothorax in England. Thorax. 2000;55:666-671.

5. Ay AA, Ulucanlar H, Ay A, Pirhan Y. Nadir bir solunum sıkıntısı nedeni olarak yașlı hastada Bochdalek hernisi, Kocaeli Tıp Dergisi. 2013;3:24-26. 